\title{
Chronic gastrointestinal haemorrhage controlled by antifibrinolytic agents
}

\author{
J.M.T. Willoughby \\ Department of Medicine, Lister Hospital, Stevenage, Herts SGI 4AB, UK.
}

\begin{abstract}
Summary: Antifibrinolytic agents are used chiefly for control of acute haemorrhage. Their applicability to chronic bleeding from inflammatory lesions of the gastrointestinal tract is illustrated by two case histories.
\end{abstract}

\section{Introduction}

Inhibitors of fibrinolysis are known to assist in the control of acute haemorrhage from ulcers in the upper gastrointestinal tract. ${ }^{1-3}$ They have also been shown to reduce chronic blood loss in ulcerative colitis. ${ }^{4,5}$ There is, however, no published record of their utility as a means of suppressing haemorrhage from the gastrointestinal tract which is recurrent over many months, despite conventional treatment of the causative lesion, and severe enough to require multiple blood transfusions. Two such cases are described below.

\section{Case reports}

\section{Case 1}

A woman aged 72 with hiatus hernia and longstanding reflux oesophagitis presented in January 1985 complaining of exertional dyspnoea. She had a microcytic anaemia with haemoglobin $5.8 \mathrm{~g} / \mathrm{dl}$. A barium enema was normal, but upper gastrointestinal endoscopy showed spontaneous haemorrhage from an inflamed distal oesophagus. There was no clinical evidence for a general bleeding disorder, and the platelet count was $133 \times 10^{9} / 1$. A haemoglobin of $15.8 \mathrm{~g} / \mathrm{dl}$ was recorded after 6 units of blood had been given, and ranitidine was prescribed at $300 \mathrm{mg}$ nightly, together with postprandial alginate/antacid. Reflux symptoms abated but in October haemoglobin had fallen to $8.3 \mathrm{~g} / \mathrm{dl}$, and iron supplements were added. Temporary improvement followed, but by December the patient was again dyspnoeic, with haemoglobin $7.7 \mathrm{~g} / \mathrm{dl}$. Another 4 units were transfused and sucralfate was added to her medication at $2 \mathrm{~g}$ twice daily. By April 1986 the

Correspondence: J.M.T. Willoughby, D.M., F.R.C.P. Accepted: 7 September 1988 anaemia had recurred, and at repeat endoscopy an ulcer was seen in the haemorrhagic zone.

After a further transfusion of 4 units, aminocaproic acid syrup was given at $3 \mathrm{~g}$ four times daily. The post-transfusion haemoglobin level of $13.7 \mathrm{~g} / \mathrm{dl}$ was maintained over the next 2 months. When aminocaproic acid was withdrawn by the manufacturer, tranexamic acid was substituted at $500 \mathrm{mg}$ twice daily, and soon reduced to half this dosage. There being no change in haemoglobin after another 2 months this treatment was stopped in September 1986. A further oesophagoscopy showed mild erythema but no friability in the previously haemorrhagic segment. On regular antacid and iron therapy over the next 15 months the patient has complained only of minimal dyspepsia, and in December 1987 haemoglobin was $15.0 \mathrm{~g} / \mathrm{dl}$.

\section{Case 2}

A woman aged 77 developed bloody diarrhoea in 1984, 2 years after undergoing radiotherapy for carcinoma of the cervix uteri. The anaemia for which 3 blood transfusions were given that year was attributed partly to this but partly also to a non-megaloblastic cause of macrocytosis which remains to be identified and has ever since prevented her achieving a normal haemoglobin. She has never bled from other sites, her liver function tests have remained normal, and her lowest platelet count was $136 \times 10^{9} / 1$ in December 1985. Barium enema was normal, but fibreoptic sigmoidoscopy showed a diffusely haemorrhagic mucosa in the rectum and sigmoid colon, with diminishing inflammation as far as $45 \mathrm{~cm}$ from the anal margin.

Blood loss continued despite treatment with oral sulphasalazine $3 \mathrm{~g}$ /day (later replaced by prednisolone) and local corticosteroids. During 1985 the patient was readmitted 6 times for transfusion. 
In June 1986, after 4 further transfusions, aminocaproic acid was added to the antiinflammatory regimen at $3 \mathrm{~g}$ thrice daily, and from then all overt bleeding ceased. From September tranexamic acid was substituted at $2 \mathrm{~g}$ thrice daily. In October repeat sigmoidoscopy showed a pale friable mucosa, with minimal surface irregularity to $35 \mathrm{~cm}$, and normal appearances beyond. Tranexamic acid was stopped in December, with no clinical effect, though after 5 weeks haemoglobin had fallen to $8.8 \mathrm{~g} / \mathrm{dl}$ and a reticulocyte count was $3.7 \%$. The trend was reversed by re-prescription of tranexamic acid at $1 \mathrm{~g}$ thrice daily. Throughout 1987 this was continued, with prednisolone and oral iron, to give a reasonably constant haemoglobin level and clinical wellbeing sufficient to save the patient any further blood transfusions. In February 1988 haemoglobin was $10.5 \mathrm{~g} / \mathrm{dl}$, mean cell volume $102 \mathrm{fl}$ and reticulocytes $1.2 \%$.

\section{Discussion}

This experience suggests that chronic oozing of blood from a diffusely inflamed mucosal surface in the gastrointestinal tract may be prevented by antifibrinolytic treatment, irrespective of pathology or the site involved. Both cases described were in elderly patients whose disease had failed to respond to conventional anti-inflammatory medication. Although one had reflux oesophagitis and the other irradiation proctosigmoiditis it was intractable haemorrhage that deprived both of reasonable health and independence. The cost of this single manifestation in medical attendance, occupancy of hospital beds, and donated blood must have been substantial. From the first prescription of aminocaproic acid nearly 2 years have passed since either patient required admission to hospital. In Case 1 tranexamic acid was stopped after 5 months of antifibrinolytic therapy, but in Case 2 it has been considered advisable to continue this indefinitely, and despite the patient's need for several other drugs a dosage of $1 \mathrm{~g}$ thrice daily has been well tolerated. Although direct examination of the mucosa has failed to show gross haemorrhage since this treatment was started some microscopic loss must be assumed, since in each case maintenance of an

\section{References}

1. Cormack, F., Chakrabarti, R.R., Jouhar, A.J. \& Fearnley, G.R. Tranexamic acid in upper gastrointestinal haemorrhage. Lancet 1973, i: 1207-1208.

2. Biggs, J.C., Hugh, T.B. \& Dodds, A.J. Tranexamic acid and upper gastrointestinal haemorrhage - a double-blind trial. Gut 1976, 17: 729-734. acceptable haemoglobin level has been found to depend in part on iron supplements.

Fibrinolysis is known to occur in acute upper 3 gastrointestinal haemorrhage, ${ }^{6}$ and although no in- 0 crease in fibrinolytic activity could be detected in $\stackrel{\complement}{.}$ blood draining the site of chronic idiopathic colitis ${ }^{7}$ it $\overrightarrow{\vec{F}}$ has been found in rectal biopsies during an acute phase of both ulcerative and irradiation proctitis. ${ }^{8}$ Haemorr-듬 hage dominated the clinical picture to an unusual $\frac{\overline{\bar{c}}}{2}$ degree in both the examples of chronic gastrointestinal ${ }_{\stackrel{\alpha}{\alpha}}$ inflammation now described, but since its response to aminocaproic acid coincided in each case with $a_{\rightarrow}^{\infty}$ change in endoscopic appearances to those of quies-? cent disease it is possible that the drug served also to $\vec{\omega}$ interrupt the cycle of humoral events without which the acute inflammatory process could not have persisted so long. If in man aminocaproic acid is capable $\underline{3}$. of reversing the increase in capillary permeabilityos induced by histamine, as has been found in the $/$ guinea-pig, ${ }^{9}$ it could have acted here to limit the supply. of reactive cells to the site of tissue damage. $\vec{\infty}$ Aminocaproic acid has also been shown to inhibit the ${ }_{\circ}^{\circ}$ activation of $\mathrm{C}_{1}{ }^{10}$ and tranexamic acid to interrupt ${ }^{\circ}$ both classical and alternative complement pathways, ${ }^{11}-$ perhaps chiefly by preventing the conversion of $\mathrm{C}_{1}$ to its esterase. ${ }^{12}$ The finding from experiments in several $\stackrel{\circ}{\square}$ species that aminocaproic acid may prolong graft $\vec{\omega}$ survival $^{13}$ implies an effect on cell-mediated mechanisms that could have contributed further to the resolution of inflammatory change in these lesions?

Such cases demonstrate that when appropriate conventional medication fails to obviate the need foro repeated blood transfusion in chronic inflammatoryष disorders of the alimentary tract the addition of an $\overrightarrow{\vec{Q}}$ antifibrinolytic agent may succeed. In so far as this treatment lacks specificity it might prove an acceptable $\vec{\supset}$ substitute for diagnostic laparotomy in some elderlyo patients who are chronically disabled by gastrointes $=-\frac{1}{0}$ tinal bleeding from an unknown site.

\section{Acknowledgement}

I am grateful to Dr K.B. Greenish for keeping me informed of 3 the patient's progress in Case 2, and to Miss S. Webber of KabiVitrum Ltd for a search of the literature.
3. Stael von Holstein, C.C.S., Eriksson, S.B.S. \& Kallen, R.币 Tranexamic acid as an aid to reducing blood transfusion $\stackrel{\oplus}{-}$ requirements in gastric and duodenal bleeding. $\mathrm{Br}$ Med $\mathrm{J}$ 1987, 294: 7-10.

4. Salter, R.H. \& Read, A.E. Epsilon-aminocaproic acid therapy in ulcerative colitis. Gut 1970, 11: 585-587. 
5. Hollanders, D., Thomson, J.M. \& Schofield, P.F. Tranexamic acid therapy in ulcerative colitis. Postgrad Med J 1982, 58: 87-91.

6. Poller, L. \& Thomson, J.M. Evidence for a relationship between fibrinolysis and haematemesis. $\mathrm{Br} \mathrm{J}$ Haematol 1973, 24: 664.

7. Swan, C.H.J., Alexander-Williams, J. \& Cooke, W.T. Fibrinolysis in colonic disease. Gut 1970, 11: 588-591.

8. Kwaan, H.C., Cocco, A., Mendeloff, A.I. \& Astrup, T. Fibrinolytic activity in the normal and inflamed rectal mucosa. Scand J Gastroenterol 1969, 4: 441-445.

9. Copley, A.L. \& Carol, B. Inhibiting action of epsilon amino caproic acid on capillary permeability in guinea pigs tested with new quantitative method based on Straus' peroxidase procedure. Variance and covariance analyses. Life Sci 1964, 3: 65-76.
10. Soter, N.A., Austen, K.F. \& Gigli, I. Inhibition by $\alpha$-aminocaproic acid of the activation of the first component of the complement system. J Immunol 1975, 114: 928-932.

11. Takada, Y., Arimoto, Y., Mineda, H. \& Takada, A. Inhibition of the classical and alternative pathways by aminoacids and their derivatives. Immunology 1978, 34: 509-515.

12. Muramatu, M., Shiraishi, S. \& Fujii, S. Inhibitory effects of $\omega$-guanidino acid esters on the first component of human complement. Biochim Biophys Acta 1972, 285: 224-234.

13. Ogston, D. Antifibrinolytic Drugs. Chemistry, pharmacology and clinical usage. John Wiley and Sons, Chichester. 1984, p. 77. 